Berkala Ilmu Perpustakaan dan Informasi, Vol. 17, No. 2, Desember 2021, Hal. 181-194 https://doi.org/10.22146/bip.v17i1.1722

ISSN 1693-7740 (Print), ISSN 2477-0361 (Online)

Tersedia online dihttps://journal.ugm.ac.id/v3/BIP

\title{
LAM (Libraries, Archives, Museums) dalam preservasi pengetahuan
}

\author{
Anindya Ambar Wati ${ }^{1}$, Rahmi $^{2}$ \\ ${ }^{1,2}$ Departemen Ilmu Perpustakaan, Fakultas Ilmu Pengetahuan Budaya, \\ Universitas Indonesia, Depok, 16424, Indonesia \\ E-mail:anindya.ambar@ui.ac.id ${ }^{1}$
}

Naskah diterima: 20 April 2021, direvisi: 29 September 2021, disetujui: 5 Oktober 2021

\begin{abstract}
ABSTRAK
Pendahuluan. Artikel ini bertujuan untuk mengetahui kolaborasi Libraries, Archives, Museums (LAM) dalam pelestarian pengetahuan.

Metode penelitian. Metode yang digunakan yaitu telaah sistematis dengan pendekatan kualitatif, dan artikelartikel terseleksi yang bersumber dari Google Scholar.

Data analisis. Proses analisis terdiri dari 6 (enam) tahap yaitu 1) mapping the field through scoping review (pemetaan bidang melalui tinjauan lingkup); 2) comprehensive search (pencarian komprehensif); 3) quality assessment (penilaian kualitas); 4) data extraction (ekstraksi data); 5) synthesis (sintesis); dan 6) write up (penulisan).

Hasil dan Pembahasan. Artikel jurnal terseleksi yang dikaji dalam penelitian, mayoritas mengulas tentang kolaborasi dan kerja sama yang terjalin oleh LAM di dalam negeri maupun luar negeri. Strategi yang digunakan berdasarkan pada tujuan preservasi preventif dan preservasi kuratif sumber pengetahuan. Keterbatasan sumber daya manusia menjadi tantangan utama pelaksanaan preservasi pengetahuan oleh LAM.

Kesimpulan dan Saran. Penelitian di Indonesia sudah memunculkan kolaborasi antara LAM dalam pelaksanaan preservasi pengetahuan. Selain itu, penjabaran mengenai kolaborasi LAM yang ditemukan dalam proses preservasi pengetahuan berfokus pada preservasi preventif dan preservasi kuratif.
\end{abstract}

Kata kunci: arsip; information retrieval; museum; perpustakaan; preservasi pengetahuan

\section{ABSTRACT}

Introduction. This paper aims to determine the collaboration of LAM (Libraries, Archives, Museums) in implementing knowledge preservation.

Research Methods. A systematic review with a qualitative approach was used, and the articles were selected from Google Scholar.

Data Analysis. The data collection method consists of 6 (six) stages, 1) mapping the field through scoping review, 2) comprehensive search, 3) quality assessment, 4) data extraction, 5) synthesis, and 6) write-up.

Results and Discussion. The results indicated that the selected journal articles covered collaborations and cooperations that have been established by LAM in the country and overseas. The strategy used was based on the objective of preventive and curative preservations of knowledge. Human resources were found as a main challenge for implementing knowledge preservation by $L A M$.

Conclusion. Based on the findings, research in Indonesia has led to various collaborations between LAM in implementing knowledge preservation from both preventive preservation and curative approaches.

Keywords: archives; information retrieval; knowledge preservation; libraries; museums 


\section{A. PENDAHULUAN}

LAM (Libraries, Archives, and Museums) merupakan lembaga penyedia jasa informasi yang memiliki keterkaitan satu sama lain. Beragamnya kebutuhan informasi individu dewasa ini, menuntut ketiga lembaga tersebut untuk mampu memberikan layanan informasi yang optimal. Berdasarkan karakteristik sumber informasi yang tergolong dalam koleksi perpustakaan, kearsipan, dan museum, ketiga lembaga ini harus mampu menjawab kebutuhan publik akan informasi yang valid. Kerja sama antara museum dan perpustakaan tidak hanya sebatas pada penyediaan sumber informasi, akan tetapi lebih dari itu, museum dan perpustakaan dapat menjadi pusat perkembangan sosio-politik. Museum dan perpustakaan merupakan media yang tepat dalam pemberdayaan komunitas lokal di mana kolaborasi antara keduanya dapat membangun komunitas lokal dalam menyelesaikan permasalahan sosial atau pun yang berkaitan dengan politik (Taylor, 2020).

Library atau perpustakaan berdasarkan UU No. 43 tahun 2007 berfungsi sebagai media pendidikan melalui peningkatan literasi masyarakat, penelitian dengan tersedianya layanan referensi bagi para peneliti, pelestarian koleksi yang terhimpun, informasi dengan terjaminnya ketersediaan sumber informasi yang valid, dan rekreasi melalui bentuk layanan dan koleksi hiburan serta fungsi sosial dari perpustakaan sebagai wadah terbentuknya sosialisasi antar pemustaka dalam memperoleh informasi.

Archive atau arsip berdasarkan UndangUndang No. 43 Tahun 2009 merupakan rekaman kegiatan atau peristiwa dalam berbagai bentuk dan media sesuai dengan perkembangan teknologi informasi dan komunikasi. Arsip dibuat dan diterima oleh lembaga negara, pemerintahan daerah, lembaga pendidikan, perusahaan, organisasi politik, organisasi kemasyarakatan, dan perseorangan dalam pelaksanaan kehidupan bermasyarakat, berbangsa, dan bernegara. Selain itu, berdasarkan SNI-ISO 15489 bukti kegiatan pekerjaan dan sekaligus aset informasi dapat dikatakan sebagai arsip. Arsip dibedakan dari aset informasi lain berdasarkan perannya sebagai bukti transaksi pekerjaan dan peran metadata dalam pengelolaannya. Jadi, dapat diketahui bahwa arsip merupakan aset informasi yang memuat nilai bukti atau evidence yang dapat dimanfaatkan serta diakses oleh publik. Untuk itu adanya preservasi jangka panjang mendukung kegunaan arsip khususnya informasi sejarah yang dimuat.

Museum, yang diatur dalam Peraturan Pemerintah Nomor 66 Tahun 2015 merupakan lembaga yang berfungsi dalam melindungi, mengembangkan, memanfaatkan koleksi, serta mengomunikasikannya kepada masyarakat. Adapun berdasarkan peraturan pemerintah tersebut yang dimaksud dengan koleksi museum yakni benda, bangunan, serta struktur yang termasuk dalam cagar budaya dan hasil budaya yang memiliki nilai kesejarahan.

Bukan hal yang mustahil bagi ketiga lembaga informasi ini untuk saling mendukung dan membangun jejaring satu sama lain. Peneliti terdahulu menjelaskan bahwa adanya merger yang melibatkan museum, lembaga kearsipan, dan perpustakaan sejatinya dapat dilakukan. Hal yang perlu diperhatikan ialah proses pengelolaan koleksi dari museum oleh lembaga kearsipan, karena terdapat beberapa objek koleksi museum yang memiliki deskripsi khusus untuk kemudian dapat dimanfaatkan oleh publik (Nemmers, 2018). Kolaborasi LAM dalam proses preservasi pengetahuan ini juga ditujukan sebagai bentuk pelestarian warisan budaya nasional yang dituangkan dalam bentuk sumber pengetahuan. Selain itu, juga memunculkan peluang untuk pengembangan cara produktif serta strategi dalam meningkatkan akses publik yang jauh lebih besar pada sumber pengetahuan.

Terkait dengan akses publik, maka information retrieval menjadi landasan yang diperhatikan pula dalam kolaborasi LAM ini. Information retrieval melibatkan proses pemilihan informasi dari media penyimpanan pengetahuan. Pengetahuan dasar dan pemahaman tentang tools yang mendukung temu kembali untuk memfasilitasi akses informasi (Anyim, 2020). Dapat diperoleh pemahaman bahwa tenaga profesional yang 
terlibat dalam mengelola koleksi sumber informasi baik di perpustakaan, lembaga kearsipan, dan museum dituntut untuk memiliki kompetensi yang mumpuni, dengan begitu ketika dihadapkan dengan koleksi yang berbeda dan membutuhkan perlakuan khusus mereka dapat mengelola sumber informasi tersebut dengan baik (Riggs, 2017).

Information retrival menjadi indikator yang diperhatikan dalam mengakses informasi relevan pada LAM. Efektivitas sebuah lembaga informasi ditentukan oleh kemampuan untuk menyediakan media yang memudahkan dalam mengakses dan memperoleh informasi. Dengan demikian, masyarakat secara aktif dapat mencari dan menemukan kembali sumber informasi yang dibutuhkan (Afebende, 2019).

Sejalan temuan di atas, kolaborasi dan kerja sama yang baik oleh LAM begitu penting. Mengingat ketiga lembaga ini memiliki bidang kerja yang tidak jauh berbeda, yakni jika dilihat dari sudut pandang dokumentasi, perpustakaan, arsip, dan museum memiliki kaitan erat khususnya dalam kegiatan dokumentasi secara luas. Kegiatan tersebut terdiri dari proses mencatat, menyimpan, merawat, mengelola koleksi, dan menyajikan serta mengomunikasikan kepada publik. Sehingga proses preservasi pengetahuan akan berjalan secara optimal (Suryagung, 2018).

Adapun penelitian terdahulu berfokus pada kajian mengenai konsep LAM atau GLAM yang diterapkan pada lembaga informasi. Fitrina (2017) menemukan bahwa aspek kebijakan atau regulasi di Indonesia belum mampu mewujudkan GLAM sebagai lembaga informasi yang dapat bersatu. Penelitian Suryagung (2018) menghasilkan temuan bahwa kerja sama LAM dalam dunia kearsipan merupakan suatu yang dapat diwujudkan karena aspek dokumentasi yang hampir dilaksanakan oleh ketiga lembaga informasi tersebut. Sementara Pratiwi (2019) memperoleh data bahwa konsep GLAM yang diterapkan dapat menarik minat dan antusiasme masyarakat dalam mengakses koleksi informasi.

Beranjak dari penelitian tersebut diketahui bahwa kajian mengenai kolaborasi LAM dalam preservasi pengetahuan masih terbatas.
Penelitian ini dapat menjadi acuan serta dianggap relevan dalam penentuan agenda riset selanjutnya. Penelitian ini bertujuan menampilkan sejauh mana kolaborasi LAM dalam preservasi pengetahuan saat ini di Indonesia, bentuk strategi yang dilakukan, dan kendala yang ditemukan melalui proses identifikasi secara eksplisit.

\section{B. TINJAUAN PUSTAKA Preservasi Pengetahuan}

Preservasi pengetahuan merupakan upaya dalam melestarikan pengetahuan yang ada pada suatu institusi. Preservasi pengetahuan merupakan upaya yang dilakukan agar pengetahuan yang telah terakumulasi terjaga dan tetap berada dalam suatu organisasi. Adapun rangkaian proses preservasi pengetahuan mencakup selecting, collecting, storing, actualizing, protecting, dan accessing. Tahap pertama yakni pemilihan (selecting) pada tahap ini, sumber pengetahuan serta jenis pengetahuan dipilih untuk kemudian dilakukan preservasi. Setelah melalui proses pemilihan, pengetahuan tersebut dipetakan dan dikategorikan lalu dikumpulkan (collecting), selanjutnya pengetahuan yang telah dikategorikan dan dikumpulkan disimpan (storing) berdasarkan format yang sesuai dengan kebutuhan, agar pengetahuan tersebut dapat diaktualisasi (actualizing). Bentuk kegiatan aktualisasi ialah mentoring oleh pemilik pengetahuan. Dengan begitu perlindungan terhadap pengetahuan dapat dijalankan dengan baik (protecting), sebagai langkah untuk menghindari beberapa hal yang mengakibatkan timbulnya penyimpangan serta hilangnya pengetahuan. Tahap terakhir, bentuk pengetahuan yang telah disimpan dapat dimanfaatkan oleh organisasi melalui kemudahan akses (accessing) bagi masyarakat luas (Primadesi, 2013).

\section{IFLA (International Federation of Library Associations and Institutions)}

IFLA yang merupakan institusi perpustakaan tertinggi dan telah tergabung bersama 5 institusi internasional yakni ICA (International Council Archives), CCAAA (The 
Coordinating Council Audiovisual Archives Associations), dan ICOM (International Council of Museums), serta ICOMOS (International Council on Monuments and Sites) yang setuju untuk mengadakan kerja sama dan bertransformasi menjadi satu kesatuan dengan nama LAMMS (Library, Archives, Museums, Monuments, and Sites). Adapun tujuan utama dibentuknya kerja sama dari berbagai organisasi ini yaitu untuk lebih menggali dan mengembangkan berbagai isu dan fenomena terkait copyright, pengadaan perpustakaan digital secara global, standardisasi, political lobby, serta preservasi dan perlindungan warisan budaya.

\section{ELAG (European Library Automation Group)}

ELAG adalah konferensi utama Eropa tentang penerapan teknologi informasi di perpustakaan dan pusat dokumentasi. Selama lebih dari tiga puluh tahun, Konferensi ELAG (European Library Automation Group) telah memberikan kesempatan kepada perpustakaan dan profesional TI untuk mendiskusikan teknologi baru, meninjau perkembangan yang sedang berlangsung, dan bertukar praktik terbaik. Peserta ELAG mencakup lebih dari 670 anggota di 27 negara di seluruh Eropa. Organisasi ini membuat repositori yang memuat berbagai informasi dan kegiatan berbasis digital. Bentuk konten informasi terdiri dari report serta konsolidasi yang berasal dari lembaga arsip, perpustakaan, serta museum (LAM).

\section{NOKS (The cultural historical database of the} North of Jutland)

NOKS adalah singkatan dari Nordjyllands Kulturhistoriske Søgebase (The cultural historical database of the North of Jutland), yang merupakan database yang berisi materi tentang sejarah budaya Jutlandia Utara. Hal ini untuk memberikan pengguna kemungkinan mencari materi di ketiga institusi yang berbeda dengan satu pencarian dengan mencari di catatan katalog digital yang telah dibuat di arsip, perpustakaan dan museum di bagian utara Denmark. Selain itu, tujuan dari proyek ini adalah untuk mengumpulkan entri untuk semua bahan dalam bidang sejarah budaya, arsip, barang museum, barang cetakan, foto, rekaman, film dan kaset video dan lainnya. NOKS membentuk institusi kerja sama yang dinamakan ABM (Archive, Biblioteker (library), and Museums) yang ditujukan bagi pengguna dalam melakukan pencarian pada ketiga lembaga informasi ini melalui satu kali pencarian.

\section{METODE PENELITIAN}

Metode yang diaplikasikan dalam penelitian ini ialah metode telaah sistematis atau sistematic review, merupakan komprehensif dari semua artikel yang diterbitkan yang dipilih untuk menjawab pertanyaan tertentu menggunakan metode sistematis dalam mengidentifikasi studi yang relevan untuk meminimalkan bias dan kesalahan (Jesson, 2011). Metode penelitian telaah sistematis ini biasa digunakan dalam kajian ilmu kesehatan namun seiring perkembangan ilmu pengetahuan yang semakin pesat, telaah sistematis juga dapat diadaptasi untuk penelitian bidang ilmu sosial. Dalam penelitian ini, proses sintesis berbagai literatur yang relevan dilakukan khususnya yang terkait dengan preservasi pengetahuan oleh LAM (Libraries, Archives, Museums). Berikut tahapan telaah sistematis dimuat pada gambar 1.

\section{Menentukan Pertanyaan Penelitian}

Berdasarkan pada fase pertama yakni mapping the field through a scoping review, maka dapat dilihat bahwa fokus dari penelitian ini ialah untuk mengetahui proses preservasi pengetahuan yang dilaksanakan oleh perpustakaan, lembaga kearsipan, dan museum serta kolaborasi yang terjalin antara ketiga lembaga informasi tersebut. Penentuan batasan penelitian serta penyusunan pertanyaan penelitian menggunakan search tool PICOC (Population, Intervention, Comparison, Outcome, Context) dari Petticrew \& Roberts (2008) yang dapat diaplikasikan pada penelitian dengan metode telaah sistematis bidang sains sosial. Batasan penelitian ini digunakan dalam mendukung efektivitas penelusuran artikel yang relevan dalam menjawab pertanyaan penelitian. 
Berikut susunan pertanyaan penelitian ditampilkan pada Tabel 1.

Berdasarkan penggunaan search tool PICOC pada Tabel.1, berikut pertanyaan penelitian yang telah ditetapkan.

Pertanyaan Apa saja strategi yang digunakan

1(Q1): dalam preservasi pengetahuan yang diterapkan oleh LAM di Indonesia?

Pertanyaan Apa saja tantangan yang ditemukan

2(Q2): dalam preservasi pengetahuan yang diterapkan oleh LAM di Indonesia?

Pertanyaan Bagaimana kolaborasi yang terjalin

$3(\mathrm{Q} 3)$ : dalam preservasi pengetahuan yang diterapkan oleh LAM ?

\section{Kriteria Inklusi dan Eksklusi}

Identifikasi dilakukan melalui implementasi kriteria inklusi dan eksklusi bagi artikel jurnal yang ditemukan. Hal tersebut sebagai usaha menjamin artikel yang digunakan merupakan artikel yang relevan dan memiliki kesesuaian dengan konteks kajian penelitian. Kriteria bagi artikel yang dipilih, merupakan artikel yang menjelaskan pelaksanaan, strategi, dan tantangan dalam proses preservasi pengetahuan oleh LAM (Libraries, Archives, Museums). Lalu, artikel jurnal yang dipublikasi menggunakan Bahasa Indonesia, dan yang terakhir yaitu semua artikel jurnal yang telah dipublikasikan mulai tahun 2019-2020.

\section{Menentukan keyword pencarian}

Strategi dalam melakukan pencarian dibangun melalui penentuan kata kunci berdasarkan Boolean Logic melalui penerapan istilah OR, AND dan NOT. Terdapat tiga kriteria yang digunakan untuk mendukung proses identifikasi artikel artikel yakni population, intervention, dan method. Maka, diperoleh struktur istilah pencarian yaitu: (preservasi pengetahuan OR pelestarian pengetahuan) AND (perpustakaan OR lembaga kearsipan OR Museum) AND (kolaborasi OR strategi OR tantangan).

\section{Sumber Literatur}

Fase kedua yakni comprehensive search, proses pencarian literatur diperoleh berdasarkan penelitian terdahulu yang bersumber dari database Google Scholar (http://scholar.google.com/). Google Scholar menawarkan kemudahan dalam memfasilitasi proses pencarian sumber referensi seperti artikel atau jurnal ilmiah. Pertimbangan selanjutnya yakni, Google Scholar termasuk dalam pemeringkatan Webometrics dan H-Index dalam memberikan referensi serta sumber pembelajaran dalam mendukung pendidikan berdasarkan kriteria excellence dan openess sehingga mampu dipertanggungjawabkan secara ilmiah.

\section{Penilaian Kualitas Hasil Penelusuran}

Fase ketiga yaitu, quality assessment. Penilaian kualitas hasil penelusuran bertujuan untuk memudahkan dalam menentukan artikel jurnal dengan melihat relevansi data yang akan digunakan. Proses penyusunan pertanyaan untuk menilai artikel jurnal berdasarkan lima aspek (Jesson, 2011) yaitu: 1) Study's aims (apakah tujuan penelitian telah sesuai dengan topik penelitian); 2) Context (apakah konteks penelitian telah sesuai dengan topik penelitian); 3) Rationale (apakah penelitian dilakukan secara rasional); 4) Methods (apakah metode yang digunakan sesuai dengan topik penelitian); 5) Findings (apakah penelitian ini menjelaskan pelaksanaan preservasi pengetahuan oleh LAM).

\section{HASIL DAN PEMBAHASAN \\ 1. Hasil}

Hasil yang ditemukan berpedoman pada keyword pencarian melalui database jurnal ilmiah Google Scholar ditemukan sebanyak 149 artikel. Selanjutnya, dilakukan tahap seleksi berdasarkan kriteria eksklusi konten artikel yang tidak relevan dengan topik penelitian, maka terdapat 11 artikel yang memiliki kesesuaian dan relevan untuk diikutsertakan kemudian ditinjau. Ekstraksi data yang diperoleh berdasarkan sumber artikel dan full reference, penulis dan institusi, serta topik utama penelitian.

\section{Pertanyaan penelitian (Research question)}

Melalui metode telaah sistematis yang telah disusun, langkah selanjutnya yakni melakukan 
review atas data primer yang telah dihimpun. Selanjutnya dilakukan identifikasi temuan dari artikel jurnal sebagai data studi primer yang sesuai dengan research question dalam penelitian. Rincian dari artikel jurnal terseleksi dimuat dalam Tabel 2.

Berdasarkan Tabel 2 hasil penelusuran yang mengacu pada metode telaah sistematis, menunjukkan bahwa sebagian besar penelitian mengenai preservasi pengetahuan oleh LAM menerapkan metode kualitatif. Hal tersebut ditunjukkan pada 9 artikel terseleksi (J1; J2; J3; J5; J6; J7; J8; J9; J11). Adapun satu artikel (J4) menerapkan metode studi literatur, dan satu artikel (J10) yang menerapkan metode partisipatoris. Penetapan publikasi artikel pada tahun 2019 - 2020 turut berpengaruh dalam distribusi tahun artikel. Hasil temuan menunjukkan dari 11 artikel yang ditemukan, sebanyak 9 artikel diterbitkan pada tahun 2020 (J1; J2; J3; J4; J5; J6; J7; J8; J10). Sementara 2 artikel lainnya (J9; J12) terbit pada tahun 2019.

\section{Q1: Apa saja strategi yang digunakan dalam preservasi pengetahuan yang diterapkan oleh LAM di Indonesia?}

Peluang dan manfaat dari adanya kolaborasi LAM dalam pelaksanaan preservasi pengetahuan ini yaitu dapat memaksimalkan proses penyebaran pengetahuan, pelestarian warisan budaya, serta mendukung pelaksanaan pendidikan dan pengajaran berbasis objek fisik. Dalam pelestarian pengetahuan, strategi preservasi preventif lebih banyak dilakukan $(\mathrm{J} 2$, J3，J4，J5，J6，J7，J8，J9，J10). Tindakan preservasi terdiri dari preservasi preventif maupun kuratif. Preservasi preventif terdiri dari proses pengaturan, pencegahan serta perlindungan terhadap pengetahuan agar terhindar dari musibah yang berisiko dan tidak diharapkan. Adapun preservasi kuratif bertujuan memperbaiki obyek pengetahuan baik yang telah rusak maupun bertendensi pada bahaya kerusakan. Adapun distribusi strategi preservasi pengetahuan yang diterapkan oleh LAM di Indonesia berdasarkan artikel yang sesuai terlihat pada Gambar 2.

Berdasarkan temuan identifikasi artikel terseleksi, preservasi preventif lebih banyak dilakukan, terhadap pengetahuan dari musibah yang tidak diharapkan yang bertendensi pada rusak atau hilangnya pengetahuan baik tacit maupun eksplisit. Terdapat beberapa jenis proses preservasi preventif yang diaplikasikan yaitu, melakukan alih media penyimpanan (mikrofilm), digitisasi, dan membuat website khusus koleksi langka dari lembaga informasi terkait. Selain itu, preservasi preventif terhadap pengetahuan tacit juga dilakukan (J6), melalui arsip komunitas yang dapat merekam dan memberikan nilai evidence terhadap pengetahuan yang dimuat.

Kecenderungan artikel jurnal terseleksi menunjukkan bahwa tujuan proses preservasi yang dilaksanakan ialah mencegah sumber pengetahuan rusak ataupun hilang yang tercantum pada 9 artikel terseleksi (J2, J3, J4, J5, J6, J7, J8, J9, J10). Selain itu, sebagai langkah proteksi terhadap hal yang tidak diinginkan, baik dari unsur alam, teknologi, ataupun manusia, pelaksanaan preservasi kuratif juga dilakukan untuk memperbaiki objek pengetahuan yang telah mengalami kerusakan atau memiliki potensi kerusakan. Hal tersebut tercantum pada 5 artikel jurnal terseleksi (J1, J5, J7, J8, J11). Implementasi preservasi kuratif dilakukan terhadap pengetahuan eksplisit pada media tertentu, seperti manuskrip, naskah kuno, dan dokumen literer, melalui proses fumigasi, pemberian portepel, maupun penjilidan.

\section{Q2: Apa saja kendala yang ditemukan dalam pelaksanaan preservasi pengetahuan oleh LAM?}

Temuan berdasarkan identifikasi artikel terseleksi, diketahui 3 faktor yang dianggap sebagai tantangan dalam preservasi pengetahuan oleh LAM. Ketiga faktor tersebut mengenai terbatasnya SDM, sarana dan prasarana, dan anggaran. Dalam aspek SDM keterbatasan sumber daya, minimnya sinergitas stakeholder serta, rendahnya kesadaran masyarakat terkait dengan urgensi preservasi pengetahuan komunitas oleh LAM merupakan fokus utama yang ditemukan. Hal tersebut ditunjukkan oleh 8 artikel terseleksi (J2, J3, J5, J6, J7, J8, J10, J11). Dalam pelaksanaan preservasi pengetahuan, identifikasi terhadap 
kebutuhan masyarakat akan sumber pengetahuan harus dilaksanakan secara tepat. Khususnya pada proses seleksi, profesional informasi dapat mendampingi masyarakat untuk terlibat dalam penilaian kebutuhan agar pengetahuan yang dilestarikan memiliki nilai yang mampu merepresentasikan budaya serta identitas masyarakat. Oleh karena itu, LAM sebagai lembaga informasi dituntut untuk mampu mengupayakan kolaborasi yang berorientasi pada pengetahuan yang sesuai dengan masyarakat serta melestarikan sumber pengetahuan yang memperkuat budaya di lingkungan masyarakat.

Faktor selanjutnya yang menjadi tantangan preservasi pengetahuan oleh LAM dengan nilai dari 6 artikel terseleksi adalah faktor terbatasnya sarana dan prasarana dalam proses pelestarian pengetahuan oleh LAM (J1, J2, J4, J5, J8, J9). Fokus utama dari kendala yang muncul pada aspek sarana dan prasarana ialah lingkungan serta terbatasnya media (tools) yang mendukung proses pelestarian sumber pengetahuan. Lalu, kendala yang muncul akibat terbatasnya anggaran ditemukan pada 3 artikel jurnal terseleksi. Berikut distribusi faktor yang dianggap sebagai tantangan pada pelaksanaan preservasi pengetahuan oleh LAM berdasarkan artikel terseleksi pada Gambar 3.

\section{Q3: Bagaimana kolaborasi dalam pelaksanaan preservasi pengetahuan oleh LAM?}

LAM sebagai lembaga informasi memiliki kapasitas yang sama untuk membantu satu sama lain, serta saling bekerja sama dalam menemukan cara terbaik untuk mengatasi tantangan dari segi fiskal, administratif, serta program preservasi pengetahuan. Terlaksananya komunikasi yang intens seputar preservasi pengetahuan menciptakan suasana yang interaktif dan partisipatif baik dari LAM maupun dengan masyarakat. Hal tersebut bermuara pada munculnya inspirasi untuk menghasilkan peluang kolaboratif yang lebih baik dalam pelaksanaan preservasi pengetahuan. Berdasarkan temuan dari artikel terseleksi mengenai kolaborasi yang dilakukan dalam proses preservasi pengetahuan oleh
LAM, teridentifikasi bahwa kolaborasi terjalin pada lembaga dalam negeri ataupun luar negeri. Distribusi kolaborasi pada lembaga dalam negeri maupun luar negeri dapat dilihat pada Gambar 4.

Diketahui bahwa kolaborasi yang terjalin dengan lembaga dalam negeri ditunjukkan pada 7 artikel terseleksi (J1, J4, J6, J7, J8, J10, J11). Lembaga dalam negeri yang berkolaborasi dalam proses preservasi pengetahuan oleh LAM yaitu, Perpustakaan Nasional RI, ANRI, Perpustakaan Daerah, serta universitas di Indonesia. Tujuan dari adanya kolaborasi yaitu agar proses preservasi pengetahuan berjalan secara efektif. Pendampingan oleh tenaga ahli dalam meningkatkan kualitas sumber daya manusia serta saling bekerja sama dalam melakukan preservasi pengetahuan pada koleksi yang berjumlah banyak. Lalu, identifikasi mengenai kolaborasi dengan lembaga luar negeri terdapat pada artikel terseleksi (J1, J3). Lembaga luar negeri yang terlibat ialah Cornell University, Leiden University, dan British Library. Cornell University dan Leiden University aktif dalam kerja sama preservasi pengetahuan yang dimuat pada manuskrip, serta naskah kuno kesejarahan. Lembaga tersebut memberikan dukungan sarana dan prasarana dalam pelestarian naskah kuno. Adapun British Library menjalin kerja sama melalui berbagi koleksi yang dapat menjadi sumber sekunder terhadap pengetahuan yang telah dilestarikan.

\section{Pembahasan}

Preservasi pengetahuan oleh LAM (Libraries, Archives, Museums) merupakan wujud dari peranan LAM sebagai lembaga informasi. Bentuk tanggung jawab LAM sebagai lembaga informasi yakni menjamin terpenuhinya kebutuhan informasi publik. Koleksi yang memuat pengetahuan harus dijaga dan dilindungi, untuk menghindari adanya penyimpangan atau hilangnya pengetahuan. Dengan begitu, pelaksanaan kegiatan yang bertujuan untuk melindungi serta menjaga pengetahuan penting untuk diadakan. Pengetahuan yang telah tersimpan secara otomatis harus dimanfaatkan oleh organisasi yang menyimpannya melalui kemudahan akses 
(accessing) secara optimal (Primadesi, 2013).

Upaya preservasi pengetahuan yang cenderung diulas dalam artikel jurnal terseleksi yakni preservasi preventif yang dilakukan oleh LAM. Disebutkan bahwa preservasi preventif meliputi kegiatan pemeliharaan sumber pengetahuan berupa koleksi bahan pustaka yang telah dikategorikan menjadi dua tahap yaitu melakukan klasifikasi koleksi dan pemeliharaan terhadap media penyimpanan (Dewi, 2020). Upaya preservasi preventif yang diaplikasikan yaitu, melakukan alih media penyimpanan (mikrofilm), digitisasi, serta membuat website khusus koleksi langka dari lembaga informasi terkait (Nofrizal, 2020). Adapun preservasi preventif terhadap pengetahuan tacit dilakukan, melalui arsip komunitas yang dapat merekam dan memberikan nilai evidence terhadap pengetahuan yang dimuat (Lavenia, 2020). Preservasi pengetahuan merupakan bagian dari tanggung jawab LAM untuk memastikan bahwa generasi sekarang dan yang akan datang dapat mengakses baik warisan dokumenter maupun tekstual yang tersedia di ketiga lembaga informasi ini. Preservasi pengetahuan ini bermaksud untuk melindungi sumber pengetahuan agar tetap terjaga kelestariannya agar senantiasa dalam kondisi yang cukup baik sehingga dapat digunakan oleh generasi yang akan datang.

Preservasi pengetahuan tradisional mencakup penyimpanan pengetahuan lalu disebarluaskan melalui LAM sebagai lembaga informasi. Ada pula publikasi terhadap nilai, serta kontribusi dari tenaga profesional informasi (pustakawan atau arsiparis) juga masyarakat sekitar untuk menghindari terjadinya penyalahgunaan terhadap sumber pengetahuan. Tenaga ahli serta tokoh yang dituakan dalam masyarakat dapat terlibat dalam preservasi pengetahuan untuk mendukung terciptanya proses mentoring yang kondusif. Klasifikasi pengetahuan, manajemen, serta akses informasi juga menjadi unsur yang membangun terlaksananya proses preservasi pengetahuan yang efektif dan efisien.

Dalam 8 artikel terseleksi, ditegaskan bahwa sumber daya manusia memegang peranan penting dalam pelaksanaan preservasi pengetahuan oleh LAM. Salah satu artikel jurnal terseleksi menyebutkan kolaborasi antara pustakawan dan edukator museum selaku tenaga profesional juga dilakukan. Selain aspek pemahaman preservasi pengetahuan, kerja sama juga dilakukan dalam hal promosi kegiatan wisata budaya untuk mengatasi minimnya kesadaran masyarakat terhadap pentingnya pelestarian pengetahuan (J7). Selain itu, pendampingan pendigitisasian dan pengolahan lebih lanjut mengenai materi digital bagi staf ataupun pihak yang diberi tanggung jawab merupakan salah satu langkah untuk menanggulangi kendala yang ditemukan pada proses preservasi pengetahuan (Setiawan, 2020).

Kontribusi sumber daya manusia dalam preservasi pengetahuan oleh lembaga informasi ini ialah mempertimbangkan tujuan utama dari pelaksanaan preservasi pengetahuan sebagai peningkatan kapasitas individu menjadi agen informasi. Sumber daya manusia yang berkontribusi dari segi teknis serta kesadaran masyarakat yang minim menjadi tantangan dan kendala proses preservasi pengetahuan oleh LAM di Indonesia. Dalam hal ini, manajemen pengetahuan SDM juga terlibat. Untuk itu, kolaborasi antara LAM memungkinkan pengetahuan yang dimiliki oleh lembaga informasi tersebut digabungkan serta dikonvergensi menjadi pengetahuan kolektif.

Hal lain yang perlu dicermati, yakni kepemilikan dari sumber pengetahuan itu sendiri. Dalam mendokumentasikan, menyimpan, dan menyebarluaskan pengetahuan dibutuhkan hak kekayaan intelektual yang telah dibangun. Hal itu berguna sebagai syarat perizinan dalam menyebarluaskan dan mengatur tingkat akses ke berbagai jenis sumber pengetahuan. Budaya lokal dan kekayaan intelektual milik masyarakat dapat dilestarikan oleh perpustakaan, arsip, dan museum. Tujuannya agar pelaksanaan preservasi pengetahuan tidak hanya berfokus pada kegiatan dokumentasi saja, tetapi juga dalam tata kelola pengetahuan yang terdokumentasi.

Untuk itu, information retrieval turut menjadi landasan pada proses diseminasi 
pengetahuan oleh LAM (Afabende, 2019). Masyarakat dapat berkontribusi untuk menentukan bagaimana materi pengetahuan yang mereka miliki beredar dan dibagikan ke anggota masyarakat lain serta lembaga informasi lainnya. Information retrieval yang berfokus pada LAM ditunjukkan dalam bentuk pemanfaatan koleksi informasi. Kolaborasi LAM menawarkan pencarian informasi secara efektif. Oleh sebab itu, kolaborasi LAM ini dapat dikatakan sebagai suatu kegiatan yang kompleks. Karena memuat beberapa faktor yang menjadi landasan demi terwujudnya temu kembali informasi berdasarkan sumber pengetahuan yang optimal.

Kolaborasi LAM pada lingkup dalam negeri maupun luar negeri merupakan solusi alternatif yang dapat dilakukan demi terwujudnya proses preservasi pengetahuan yang terbebas dari keterbatasan sarana dan prasarana serta sumber daya ahli. Dalam artikel jurnal terseleksi menunjukkan upaya dalam preservasi pengetahuan yang dilakukan oleh lembaga informasi Rekso Pustaka melalui kolaborasi dengan ANRI dan Perpustakaan Nasional Republik Indonesia (Perpusnas RI), tapi juga pada tataran internasional seperti dengan Cornell University (Christiani, 2020). Rekso Pustaka juga mulai membangun dan memperkuat jaringan kerja sama untuk pelestarian naskah-naskah kuno yang dimiliki. Inventarisasi ulang beberapa koleksi dokumen literer kuno dilakukan, sehingga diketahui beberapa dokumen yang hilang dari daftar koleksi, dengan begitu, perlu dilakukan strategi preservasi untuk mengupayakan keutuhan koleksi dokumen literer sebagai intangible asset.

Kolaborasi yang telah dilaksanakan secara signifikan memperluas kemampuan lembaga informasi dalam mengeksplorasi, mengidentifikasi dan memanfaatkan potensi jaringan kerja sama sebagai upaya meningkatkan proses preservasi pengetahuan guna pengembangan layanan inovatif bagi masyarakat. Telah terlaksananya praktik kerja sama dengan lembaga sejenis pada tingkat internasional mencerminkan visibilitas dalam jaringan organisasi dengan tujuan yang sama.
Dalam hal ini, LAM telah merencanakan kegiatan kolaboratif dalam proses preservasi pengetahuan secara sistematis. Hal tersebut menunjukkan strategi LAM di Indonesia yang menjaga jalinan kemitraan. Kolaborasi yang terjalin antara LAM di Indonesia dengan lembaga internasional memberikan inisiatif digitalisasi, identifikasi kapasitas LAM sebagai institusi memori, serta pelestarian warisan budaya. Dengan begitu, fungsi esensial yang dimiliki ojek pengetahuan tersebut dapat dirasakan manfaatnya. Kesadaran akan peluang yang diberikan dengan adanya kolaborasi berpengaruh terhadap LAM di Indonesia dalam mengatasi permasalahan yang muncul pada proses preservasi pengetahuan khususnya terkait dengan digitasi koleksi. Analisis berdasarkan telaah sistematis ini, memungkinkan untuk mengamati pola dominan dalam pengembangan strategi kerja sama LAM di Indonesia dengan organisasi internasional.

\section{E. KESIMPULAN}

Kolaborasi yang dilakukan oleh LAM (Libraries, Archives, Museums) memiliki peranan penting dalam preservasi pengetahuan. LAM sebagai lembaga informasi dituntut untuk mampu melestarikan pengetahuan yang telah terakumulasi agar terhindar dari penyimpangan atau hilangnya pengetahuan. Telaah sistematis ini menunjukkan bahwa penelitian di Indonesia sudah banyak memunculkan kolaborasi antara LAM dalam pelaksanaan preservasi pengetahuan. Hal tersebut berdasarkan temuan artikel jurnal yang membahas kerja sama antara LAM baik pada lingkup dalam negeri maupun luar negeri. Pada lingkup luar negeri LAM di Indonesia telah bekerja sama dengan Cornel University dan Leiden University khususnya dalam pelaksanaan preservasi objek pengetahuan berupa manuskrip kuno.

Strategi preservasi yang dilakukan berdasarkan artikel jurnal terseleksi yaitu preservasi preventif dan preservasi kuratif. Dua strategi tersebut ditujukan untuk menghindari potensi bahaya kerusakan serta memperbaiki objek pengetahuan yang rusak. Tantangan yang dihadapi dalam preservasi pengetahuan oleh LAM berdasarkan identifikasi artikel jurnal 
yang paling besar disebabkan oleh faktor SDM, yakni minimnya ahli yang memahami proses preservasi, serta rendahnya kesadaran masyarakat mengenai preservasi pengetahuan. Kedua hal yang termasuk dalam kendala pada faktor SDM tersebut harus diperhatikan, karena berpengaruh dalam tahap selecting pada pelaksanaan preservasi pengetahuan di mana penilaian terhadap sumber pengetahuan dilakukan berdasarkan kebutuhan masyarakat. Faktor lain mengenai terbatasnya anggaran, serta sarana dan prasarana yang kurang memadai dalam mendukung pelaksanaan preservasi pengetahuan.

\section{DAFTAR PUSTAKA}

Afebende. (2019). Information retrieval tools and utilization of library resources by undergraduate students in federal universities. International Journal of Library and Information Science Studies, 5(2), 36-44

Anyim, W. (2020). Knowledge and use of information retrieval tools by lawyers at Miyetti Law Abuja Nigeria. International Journal of Library and Information Studies, 10(1), 37-44

Christiani, L. (2020). Preservasi, konservasi, dan restorasi dokumen di Rekso Pustaka. Jurnal ANUVA, 4(3), 371-382

Darmawan, B., Isyawati, R. (2020). Konservasi arsip media khusus di Dinas Kearsipan dan Perpustakaan Provinsi Jawa Tengah. Jurnal Ilmu Perpustakaan, 8(2), 22-31

Dewi, P. D. (2020). Pelestarian koleksi sastra Sunda di Perpustakaan Ajip Rosidi. Nusantara Journal of Information and Library Studies, 3(2), 237-251

Fitrina, C. (2017). Galery, Library, Archive, and Museum (GLAM) sebagai upaya transfer informasi. Shaut Al-Maktabah Jurnal Perpustakaan, Arsip, dan Dokumentasi, 8(2), 143-153

Hidayatullah, F., Nashihuddin, W., \& Putra, A. (2020). Kegiatan pelestarian dan promosi Candi Kimpulan di area Perpustakaan Universitas Islam Indonesia. Jurnal ANUVA, 4(1), 141-152. https://doi.org/10. 1007/978-3-030-21021-2_3
Jesson, J. K., Matheson, \& L., Lacey, M. (2011). Doing Your Lierature Review: Traditional and Systematic Techniques. SAGE publication Ltd.

Lavenia, C., Dewi, F. (2020). Archiving traditional medicine of Tribe Batak Karo at North Sumatra. Jurnal Kearsipan, 15(1), 79-91

Maryono, Pramono, M. (2020). Pengembangan website koleksi langka Perpustakaan UGM sebagai preservasi digital heritage menuju era industri 4.0. Jurnal Kajian Informasi dan Perpustakaan, 8(1), 1-20

Nemmers, J., Duckworth, \& Marcetti, B. (2018). From museum to archives: Managing the Panama Canal Museum Collection. Archives and Records, 39(1), 42-56. https://doi.org/10.1080/23257962. 2017.1407749

Nofrizal. (2020). Pelestarian manuskrip kuno melayu nusantara perspektif industries. AlAdyan Jurnal Studi Lintas Agama, 15(2), 122

Nova, N. (2020). Pelestarian koran lama dari ancaman bencana pada Depo Arsip Koran Suara Merdeka Semarang. Jurnal Ilmu Perpustakaan, 8(2), 1-11

Permana, R., Rohmiyati, Y. (2019). Analisis preservasi arsip statis tekstual sebagai upaya pelestarian arsip di Dinas Kearsipan dan Perpustakaan Kabupaten Pati. Jurnal Ilmu Perpustakaan, 6(3), 71-80

Petticrew, M., \& Roberts, H. (2008). Systematic reviews in the social sciences: A practical guide. John Wiley \& Sons.

Pradana, Y., Setyadi. (2019). Strategi perpustakaan dalam melakukan preservasi koleksi local history naskah kuno Keraton Surakarta di Dinas Kearsipan dan Perpustakaan Provinsi Jawa Tengah. Jurnal Ilmu Perpustakaan, 8(1), 1-23

Pratiwi, K. (2019). Analisis penerapan konsep GLAM (Gallery, Library, Archives, Museum) di Perpustakaan Bung Karno Blitar. Jurnal Perpustakaan Universitas Airlangga, 9(2), 53-62 
Primadesi, Y.(2013). Preservasi pengetahuan dalam tradisi lisan seni pertunjukan randai di Minangkabau Sumatera Barat. Jurnal Kajian Informasi dan Perpustakaan, 1(2), 179-187

Republik Indonesia. (2007). Perpustakaan Nasional. Undang-Undang Republik Indonesia Nomor 43 Tahun 2007 Tentang Perpustakaan. https://www.perpusnas. go.id/law.php?lang=id\&id=UndangUndang

Republik Indonesia. Arsip Nasional Republik Indonesia. (2009). Undang-Undang Republik Indonesia No.43 Tahun 2009 Tentang Kearsipan. https://jdih.anri.go.id/ peraturan/UU\%20Nomor\%2043\%20 Tahun\%202009.pdf

Republik Indonesia. Badan Standardisasi Nasional. (2016). Standar Nasional Indonesia SNI ISO 15489 Tahun 2016 Tentang Pengelolaan Arsip.
Republik Indonesia. Pemerintah Republik Indonesia. (2015). Peraturan Pemerintah Nomor 66 Tahun 2015 Tentang Museum. https://peraturan.bpk.go.id/Home/Details/ 5642

Riggs, C. (2017). The body in the box: Archiving the Egyptian mummy. Arch Sci, 17(1), 125-150

Setiawan, H. (2020). Pelatihan dan pendampingan digitisasi naskah lontar koleksi Museum Lontar Dukuh Penaban Kabupaten Karangasem Bali. Jurnal ISI Abdi Seni, 11(2), 137-144

Suryagung, P. (2018). Konsep LAM dalam dunia kearsipan. Jurnal Diplomatika, 2(2), 23-30

Taylor, K. (2020). The art museum redefined; Cooperation and collaboration. Journal of Urban Cultural Studies 21(1), 61-75 


\section{DAFTAR GAMBAR}

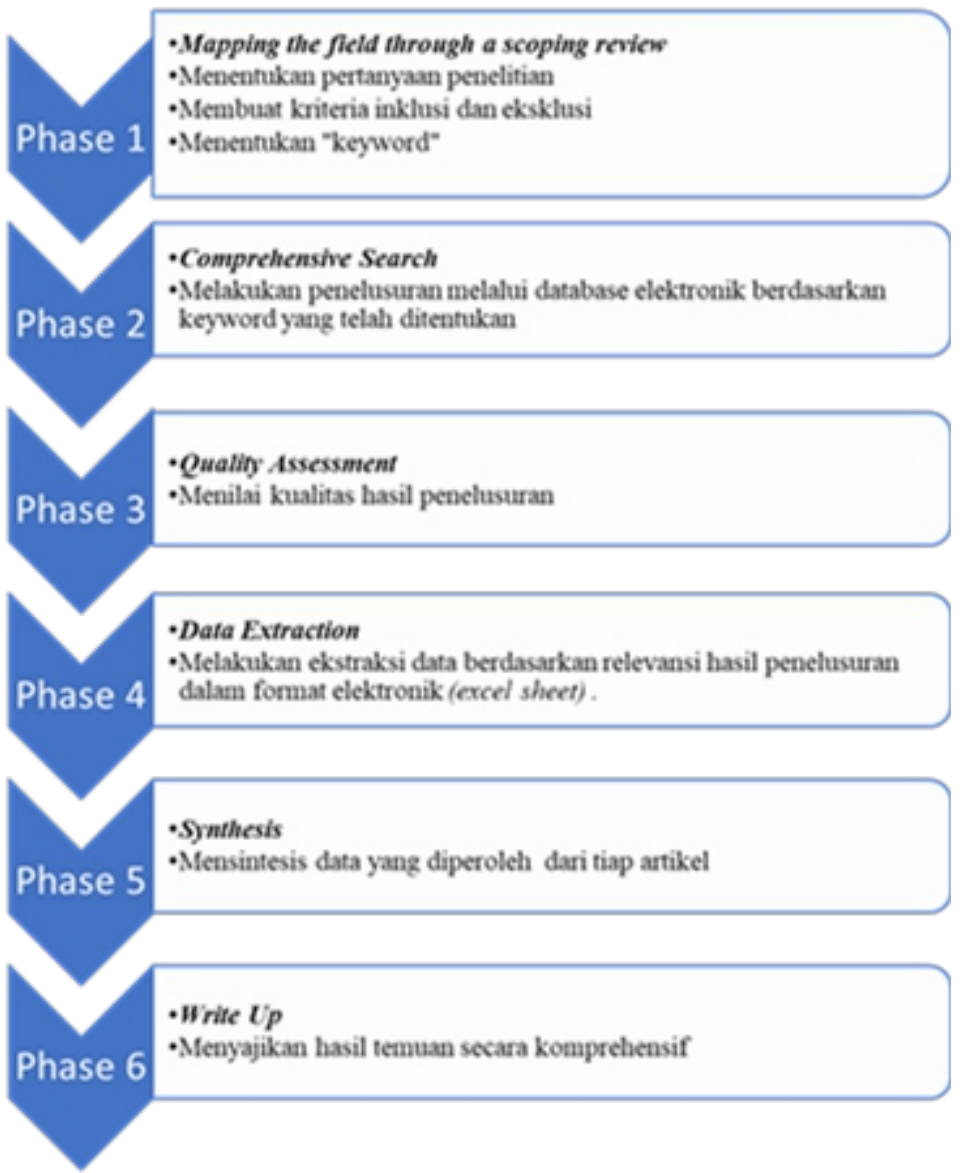

Gambar.1 Fase Sistematic Review (Jesson, 2011)

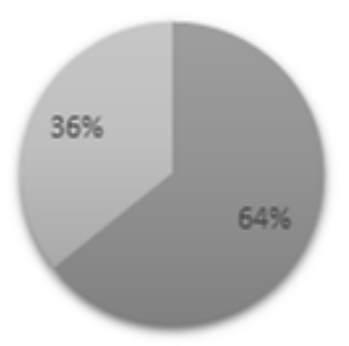

n Preservasi Preventif

Gambar.2 Strategi Preservasi Pengetahuan 


\section{DAFTAR GAMBAR}

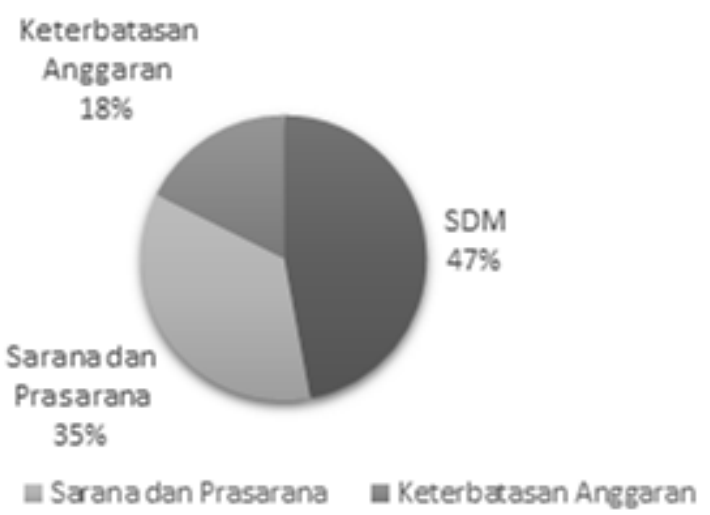

Gambar 3. Kendala dalam Preservasi Pengetahuan

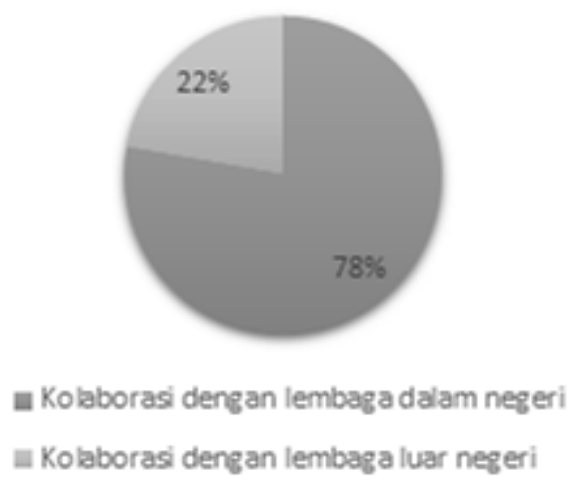

Gambar 4. Kolaborasi dalam Preservasi Pengetahuan

\section{DAFTAR TABEL}

Tabel 1. Pertanyaan Penelitian

\begin{tabular}{lc}
\hline Cakupan & Kriteria \\
\hline $\begin{array}{l}\text { Batasan pada topik penelitian mengenai kegiatan preservasi pengetahuan atau pelestarian } \\
\text { pengetahuan oleh LAM }\end{array}$ & $\begin{array}{c}\text { Population } \\
\text { Tahtervention }\end{array}$ \\
$\begin{array}{l}\text { Pelaksanaan preservasi atau pelestarian pengetahuan oleh LAM, strategi, tantangan, dan kolaborasi } \\
\text { yang dilakukan. }\end{array}$ & Outcome \\
$\begin{array}{l}\text { Review dari hasil pencarian topik penelitian mengenai preservasi pengetahuan oleh LAM di } \\
\text { Indonesia }\end{array}$ & Context \\
\hline
\end{tabular}

Sumber: Data Primer diolah, tahun 2021 


\section{DAFTAR TABEL}

Tabel.2 Hasil Penelusuran

\begin{tabular}{|c|c|c|}
\hline Kode & Judul & Penulis, Tahun / Jurnal \\
\hline $\mathrm{J} 1$ & $\begin{array}{l}\text { Preservasi, Konservasi dan Restorasi Dokumen di Rekso } \\
\text { Pustaka }\end{array}$ & Lydia Christiani, 2020/ Jurnal ANUVA , 4(3) \\
\hline $\mathrm{J} 2$ & $\begin{array}{l}\text { Pelestarian Koleksi Sastra Sunda di Perpustakaan Ajip } \\
\text { Rosidi }\end{array}$ & $\begin{array}{l}\text { Dinda Puspita Dewi, 2020/Jurnal Ilmu } \\
\text { Perpustakaan dan Informasi Nusantara, 3(2) }\end{array}$ \\
\hline $\mathrm{J} 3$ & $\begin{array}{l}\text { Pengembangan website koleksi langka Perpustakaan UGM } \\
\text { sebagai preservasi digital heritage menuju era industri } 4.0\end{array}$ & $\begin{array}{l}\text { Maryono, 2020/Jurnal Kajian Informasi dan } \\
\text { Perpustakaan, 8(1) }\end{array}$ \\
\hline $\mathrm{J} 4$ & $\begin{array}{l}\text { Pelestarian Manuskrip Kuno Melayu Nusantara Perspektif } \\
\text { Industries }\end{array}$ & $\begin{array}{l}\text { Nofrizal, 2020/Al-Adyan : Jurnal Studi } \\
\text { Lintas Agama, 15(2) }\end{array}$ \\
\hline $\mathrm{J} 5$ & $\begin{array}{l}\text { Analisis Preservasi Arsip Statis Tekstual sebagai Upaya } \\
\text { Pelestarian Arsip di Dinas Kearsipan dan Perpustakaan } \\
\text { Kabupaten Pati }\end{array}$ & Rio Permana, 2019/ ANUVA, 2 (1) \\
\hline J6 & $\begin{array}{l}\text { Pengarsipan Obat Tradisional Suku Batak Karo di Sumatera } \\
\text { Utara }\end{array}$ & $\begin{array}{l}\text { Christy Lavenia, 2020/ Jurnal Kearsipan, } \\
15(1)\end{array}$ \\
\hline $\mathrm{J} 7$ & $\begin{array}{l}\text { Kegiatan Pelestarian dan Promosi Candi Kimpulan di Area } \\
\text { Perpustakaan Universitas Islam Indonesia }\end{array}$ & $\begin{array}{l}\text { Fauzan Hidayatullah, 2020/ Jurnal ANUVA, } \\
4(2)\end{array}$ \\
\hline $\mathrm{J} 8$ & $\begin{array}{l}\text { Pelestarian Koran Lama dari Ancaman Bencana } \\
\text { pada Depo Arsip Koran Suara Merdeka Semarang }\end{array}$ & Nova, 2020/Jurnal Ilmu Perpustakaan, 8(2) \\
\hline J9 & $\begin{array}{l}\text { Konservasi Arsip Media Khusus di Dinas Kearsipan dan } \\
\text { Perpustakaan Provinsi Jawa Tengah }\end{array}$ & $\begin{array}{l}\text { Bogi Darmawan, 2020/ Jurnal Ilmu } \\
\text { Perpustakaan, 8(2) }\end{array}$ \\
\hline $\mathrm{J} 10$ & $\begin{array}{l}\text { Pelatihan dan Pendampingan Digitisasi Naskah Lontar } \\
\text { Koleksi Museum Lontar Dukuh Penaban Kabupaten } \\
\text { Karangasem Bali }\end{array}$ & $\begin{array}{l}\text { Agus Heru Setiawan, 2020/ Jurnal Abdi Seni, } \\
11(2)\end{array}$ \\
\hline $\mathrm{J} 11$ & $\begin{array}{l}\text { Strategi Perpustakaan dalam Melakukan Preservasi } \\
\text { Koleksi Local History Naskah Kuno Keraton Surakarta di } \\
\text { Dinas Kearsipan dan Perpustakaan Provinsi Jawa Tengah }\end{array}$ & $\begin{array}{l}\text { Albi Yuga Pradana, 2019/Jurnal Ilmu } \\
\text { Perpustakaan, 8(1) }\end{array}$ \\
\hline
\end{tabular}

Sumber: Data Primer diolah, tahun 2021 